\title{
Modeling and Simulation of Photovoltaic Water Pumping System
}

\author{
Taufik, Akihiro Oi \\ Electrical Engineering Department \\ Cal Poly State University \\ San Luis Obispo, CA 93407 USA \\ taufik@calpoly.edu
}

\author{
Makbul Anwari \\ Faculty of Electrical Engineering \\ Universiti Teknologi Malaysia \\ 81310 UTM Skudai, Malaysia \\ makbul@ieee.org
}

\author{
Mohammad Taufik \\ Department of Physics \\ Universitas Padjadjaran \\ Bandung 40132, Indonesia \\ mhtaufik@yahoo.com
}

\begin{abstract}
This paper presents modeling of a simple but efficient photovoltaic water pumping system. The system employs maximum power point tracker (MPPT). Two MPPT algorithms, subsystems and control methods will be modeled and simulated using Matlab and Simulink with actual irradiance data. Simulation results will be presented in terms of performance parameters such as total energy produced and total volume of water pumped per day. The results further validate that MPPT can significantly improve efficiency and performance of PV water pumping system compared to the system without MPPT.
\end{abstract}

Keywords - Water Pumping System, Renewable Energy Sources, Photovoltaic System

\section{INTRODUCTION}

Water resources are essential for satisfying human needs, protecting health, and ensuring food production, energy and the restoration of ecosystems, as well as for social and economic development and for sustainable development [1]. However, according to UN World Water Development Report in 2003, it has been estimated that two billion people are affected by water shortages in over forty countries, and 1.1 billion do not have sufficient drinking water [2]. There is a great and urgent need to supply environmentally sound technology for the provision of drinking water. Remote water pumping systems are a key component in meeting this need. It will also be the first stage of the purification and desalination plants to produce potable water. In this paper, a simple but efficient photovoltaic water pumping system is presented. It provides theoretical studies and modeling of photovoltaics (PV) and comparative study on the use of maximum power point tracker (MPPT).

\section{THE PROPOSED SYSTEM}

The water pumping system is a stand-alone $150 \mathrm{~W}$ system without backup batteries as shown in Figure 1 . The system consists of a single PV module, a maximum power point tracker (MPPT), and a DC water pump.

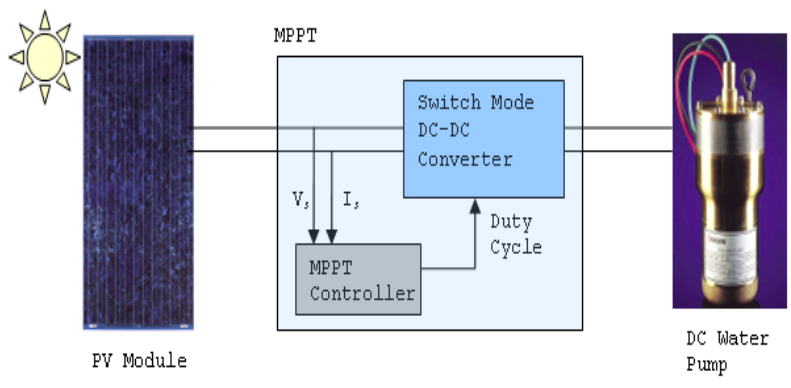

Figure 1. Block diagram of Proposed System

Maximum power point tracker (MPPT) is now prevalent in grid-tied PV power systems and is becoming more popular in stand-alone systems. Analog controllers have traditionally performed control of MPPT. However, the use of digital controllers is rapidly increasing because of their advantages over analog controllers. First, digital controllers are capable of implementing advanced algorithm with relative ease. It is far easier to code the equation, $x=y \times z$, than to design an analog circuit to do the same [3]. Digital controllers are immune to time and temperature drifts because they work in discrete, outside the linear operation. As a result, they offer long-term stability. They are also insensitive to component tolerances since they implement algorithm in software, where gains and parameters are consistent and reproducible [3]. They allow reduction of parts count since they can handle various tasks in a single chip. Therefore, a method of digital control was selected for the MPPT in the proposed system. A model of MPPT is developed on the premise that implementation in a microcontroller or a DSP will be performed, and its algorithm is readily transferable.

Two types of pumps are commonly used for PV water pumping applications: positive displacement and centrifugal [4]. Positive displacement types are used in low-volume pumps [5] and cost-effective. Centrifugal pumps have relatively high efficiency [4] and are capable of pumping a high volume of water [5]. However, the cost and complexity of these systems will be significantly higher. In general, DC motors are preferred because they are highly efficient and can be directly coupled with a PV module. Brushed types are less expensive and more common although brushes need to be replaced periodically [4]. The 
water pump selected was a submersible solar pump which is a diaphragm-type positive displacement pump equipped with a brushed permanent magnet DC motor and designed for use in stand-alone water delivery systems. It operates with a low voltage $(12 \sim 30 \mathrm{~V}$ DC), and its power requirement is as little as $35 \mathrm{~W}$ [5].

\section{MODELING OF PV MODULE}

The PV module chosen is a 72 multi-crystalline silicon solar cells in series able to provide $150 \mathrm{~W}$ of maximum power [1]. The study done in [6] shows the electric model of the PV with moderate complexity, shown in Figure 2, gives very accurate results. It consists of a current source (Isc), a diode (D), and a series resistance (Rs). The effect of parallel resistance ( $\mathrm{Rp})$ is very small in a single module, thus it is not included. To make a better model, it must also include temperature effects on the short-circuit current (Isc) and the reverse saturation current of diode (Io). It uses a single diode with the diode ideality factor (n) set to achieve the best I-V curve match.

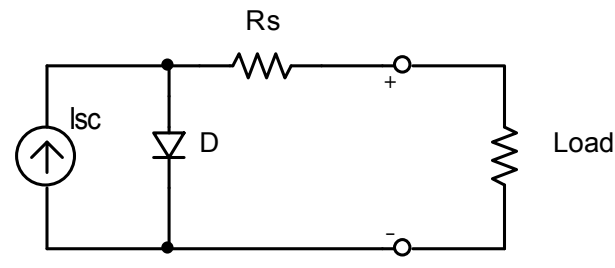

Figure 2. Equivalent circuit used in the MATLAB simulations

The following equation describes current-voltage relationship of the PV cell [6].

$$
I=I_{s c}-I_{o}\left[e^{q\left(\frac{V+I \cdot R_{s}}{n k T}\right)}-1\right]
$$

where: I is the cell current $=$ the module current, $\mathrm{V}$ is the cell voltage $=\{$ module voltage $\} \div\{\#$ of cells in series $\}, T$ is the cell temperature in Kelvin. The short-circuit current $\left(I_{s c}\right)$ was first calculated at a given cell temperature $(T)$ :

$$
\left.I_{s c}\right|_{T}=\left.I_{s c}\right|_{T_{r e f}} \cdot\left[1+a\left(T-T_{r e f}\right)\right\rfloor
$$

where: $I_{s c}$ at $T_{r e f}$ is given in the datasheet (measured under irradiance of $\left.1000 \mathrm{~W} / \mathrm{m}^{2}\right), T_{r e f}$ is the reference temperature of PV cell in Kelvin $(K)$, usually $298 K\left(25^{\circ} C\right)$, and $a$ is the temperature coefficient of $I_{s c}$ in percent change per degree temperature also given in the datasheet. The shortcircuit current $\left(I_{s c}\right)$ is proportional to the amount of irradiance. $I_{s c}$ at a given irradiance $(G)$ is:

$$
\left.I_{s c}\right|_{G}=\left.\left(\frac{G}{G_{o}}\right) I_{s c}\right|_{G o}
$$

where: $G_{o}$ is the nominal value of irradiance, which is normally $1 \mathrm{KW} / \mathrm{m}^{2}$. The reverse saturation current of diode $\left(I_{o}\right)$ at the reference temperature $\left(T_{r e f}\right)$ is given below with the diode ideality factor added:

$$
I_{o}=\frac{I_{s c}}{\left(e^{q V_{o c} / n k T}-1\right)}
$$

The reverse saturation current $\left(I_{o}\right)$ is temperature dependant and the $I_{o}$ at a given temperature $(T)$ is calculated by the following equation:

$$
\left.I_{o}\right|_{T}=\left.I_{o}\right|_{T_{r e f}} \cdot\left(\frac{T}{T_{r e f}}\right)^{\frac{3}{n}} \cdot e^{\frac{-q \cdot E_{g}}{n \cdot k}\left(\frac{1}{T}-\frac{1}{T_{r e f}}\right)}
$$

The diode ideality factor $(n)$ is unknown and must be estimated. It takes a value between one and two. However, the value of $n=1$ (for ideal diode) is used until the more accurate value is estimated later by curve fitting. The effect of varying the ideality factor is simulated in Matlab as shown in Figure 3. The series resistance $\left(R_{s}\right)$ of the PV module has a large impact on the slope of the $I-V$ curve near the open-circuit voltage $\left(V_{o c}\right)$, as shown in Figure 4. Hence, the value of $R_{s}$ is calculated by evaluating the slope of the $I$ $V$ curve at the $V_{o c}$. The equation for $R_{s}$ was derived and yields:

$$
R_{s}=-\frac{d I}{d V}-\frac{n k T / q}{I_{o} \cdot e^{q\left(\frac{V+I \cdot R_{s}}{n k T}\right)}}
$$

For open circuit voltage, $V=V_{o c}($ also $I=0)$ :

$$
R_{s}=-\left.\frac{d V}{d I}\right|_{V_{o c}}-\frac{n k T / q}{I_{o} \cdot e^{\frac{q V_{o c}}{n k T}}}
$$

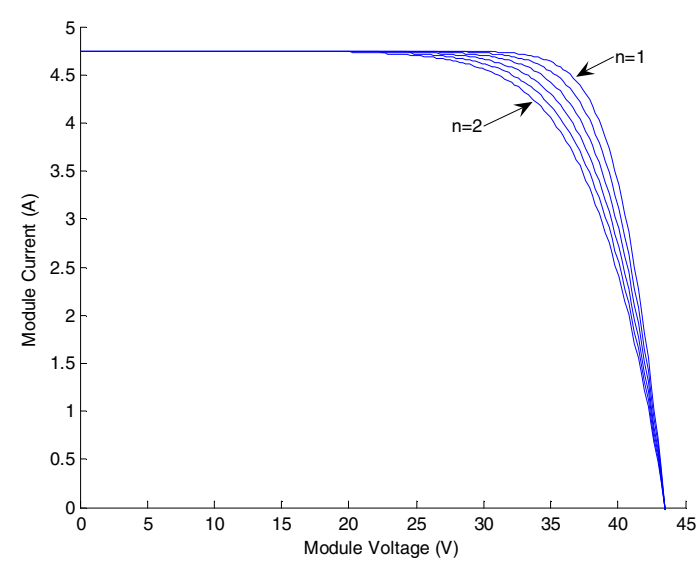

Figure 3. Effect of diode ideally factors 


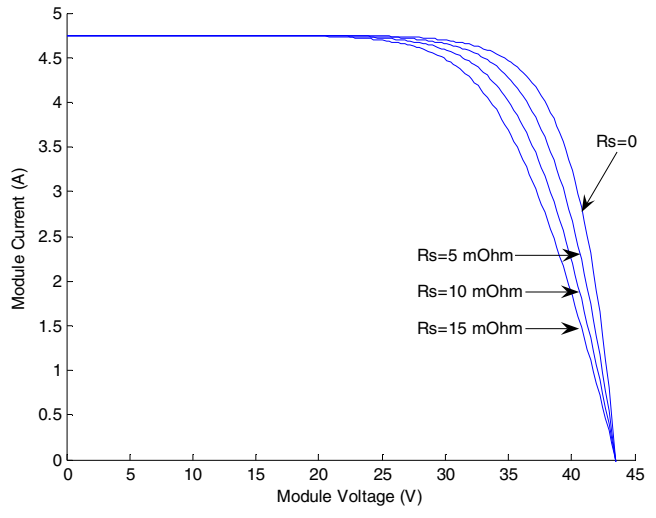

Figure 4. Effect of series resistances

Finally, the equation of $I-V$ characteristics is solved. It is, however, complex because the solution of current is recursive by inclusion of a series resistance in the model. The Newton's method was chosen for rapid convergence of the answer as shown below:

$$
I_{n+1}=I_{n}-\frac{I_{s c}-I_{n}-I_{o}\left[e^{q\left(\frac{V+I_{n} \cdot R_{s}}{n k T}\right)}-1\right]}{-1-I_{o}\left(\frac{q \cdot R_{s}}{n k T}\right) e^{q\left(\frac{V+I_{n} \cdot R_{s}}{n k T}\right)}}
$$

Figure 5 shows the $I-V$ characteristics of various module temperatures simulated by MATLAB model and provides good correspondence to data from the manufacturer's datasheet. Figure 6 depicts a point on the $I-V$ curve which yields the maximum power. This point is called a maximum power point (MPP), at which the module operates with the maximum efficiency and produces the maximum output power. It is possible to visualize the location of the MPP by fitting the largest possible rectangle inside of the $I-V$ curve as illustrated in Figure 7, and its area equal to the output power which is the product of voltage and current. It reveals that the amount of power produced by the PV module varies greatly depending on its operating condition.

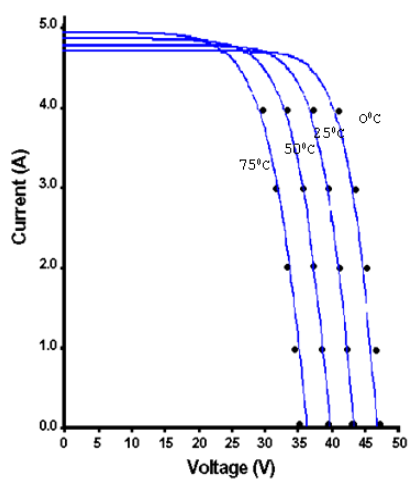

Figure 5. I-V curves for various temperatures

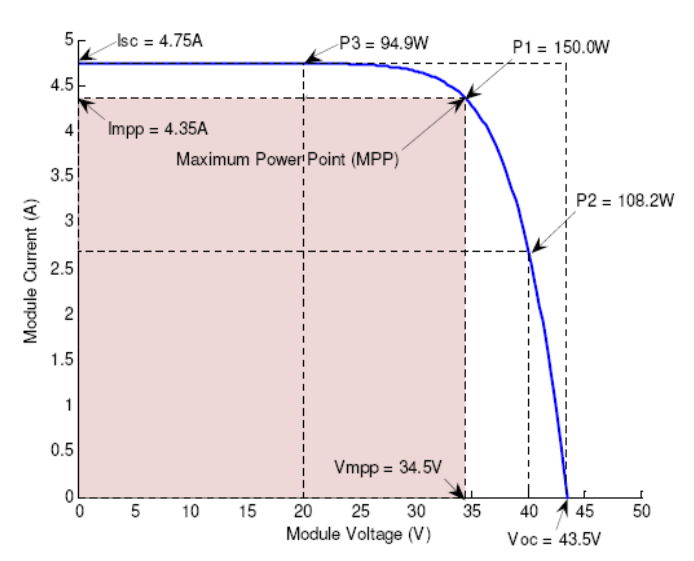

Figure 6. Simulated I-V curve of PV module

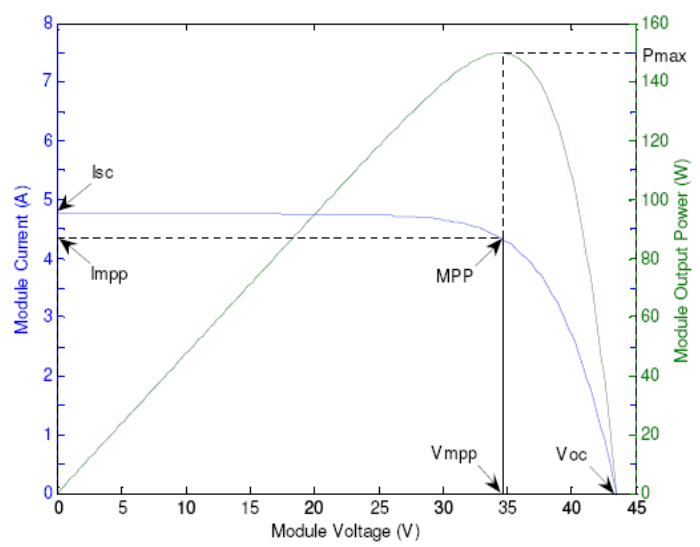

Figure 7. I-V and P-V relationships of PV module

\section{DC MOTOR MODEL}

Many PV water pumping systems employ DC motors because they could be directly coupled with PV arrays and make a system very simple. Among different types of DC motors, a permanent magnet DC (PMDC) motor is preferred in PV systems because it can provide higher starting torque. Figure 8 shows an electrical model of a PMDC motor. When the motor is turning, it produces Back EMF $(E)$ which is a voltage proportional to the angular speed of the rotor. From the equivalent circuit, the DC voltage equation for the armature circuit is:

$$
V=I \cdot R_{a}+K \cdot \omega
$$

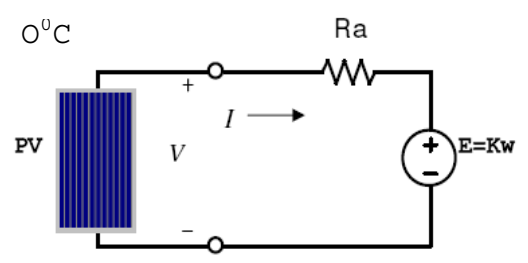

Figure 8. Electrical model of permanent magnet DC motor 
Figure 9 shows a major problem with a direct coupled PV-motor setup in efficiency because of mismatching of operating points. For this example the water pumping system would not start operating until irradiance reaches at $400 \mathrm{~W} / \mathrm{m}^{2}$. Once it starts to run, it requires as little as $200 \mathrm{~W} / \mathrm{m}^{2}$ of irradiance to maintain the minimum operation. It means that it cannot utilize a fair amount of insolation in the morning.

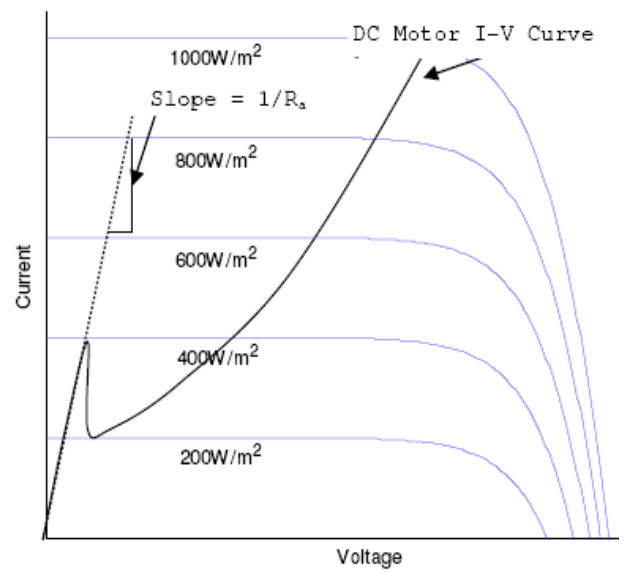

Figure 9. I-V curves with varying irradiance and a DC motor

Also, when the motor is operated under the locked condition for long time, it may result in shortening of the life of the motor due to input electrical energy converted to heat rather than to mechanical output [5]. To overcome this problem, a MPPT called a linear current booster (LCB) may be used. The MPPT maintains the input voltage and current of LCB at the MPP of PV module.

As shown in Figure 10, the power produced at the MPP is relatively low-current and high-voltage which is opposite of those required by the pump motor. The LCB shifts this relationship around and convert into highcurrent and low-voltage power which satisfies the pump motor characteristics. For example, as shown in Figure 11 , the LCB could start the pump motor as little as $50 \mathrm{~W} / \mathrm{m}^{2}$ of irradiance.

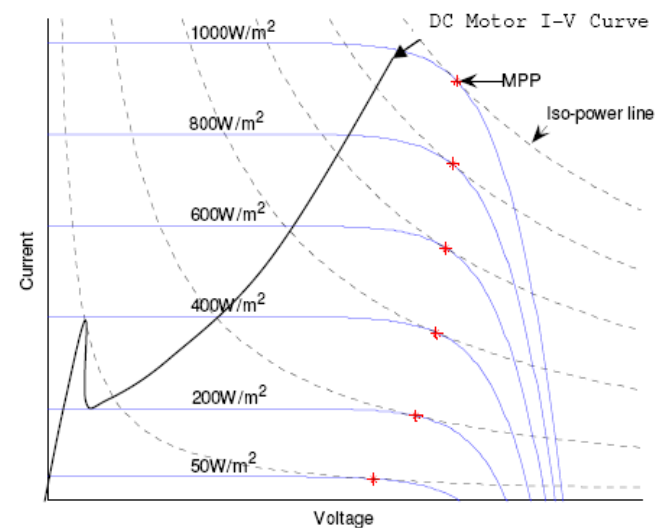

Figure 10. PV I-V curves with constant power lines (dotted) and a DC motor I-V curve

\section{SimUlation RESUlts}

The location of the MPP in the I-V plane is not known beforehand and always changes dynamically depending on irradiance and temperature. Therefore, the MPP needs to be located by tracking algorithm. There are a number of methods that have been proposed. Among different algorithms are the Perturb \& Observe and Incremental Conductance (incCond) discussed here.

On a sunny day, the irradiance level changes gradually since there is no influence of cloud. MPP tracking is supposed to be easy. As shown in Figure 11, both algorithms locate and maintain the PV operating point very close to the MPPs without much difference in their performance.

On a cloudy day, the irradiance level changes rapidly because of passing clouds. MPP tracking is supposed to be challenging. Figure 12 shows the trace of PV operating points for (a) $\mathrm{P} \& \mathrm{O}$ algorithm and (b) incCond algorithm. For both algorithms, the deviations of operating points from the MPPs are obvious when compared to the results of a sunny day. A close inspection of Figure 12 reveals that the $\mathrm{P} \& \mathrm{O}$ algorithm has slightly larger deviations overall and some erratic behaviors (such as the large deviation pointed by the red arrow). The simulation results show the efficiency of $99.3 \%$ for the $\mathrm{P} \& \mathrm{O}$ algorithm and $99.4 \%$ for the incCond algorithm. The experimental results show $96.5 \%$ \& $97.0 \%$, respectively, for a partly cloudy day.
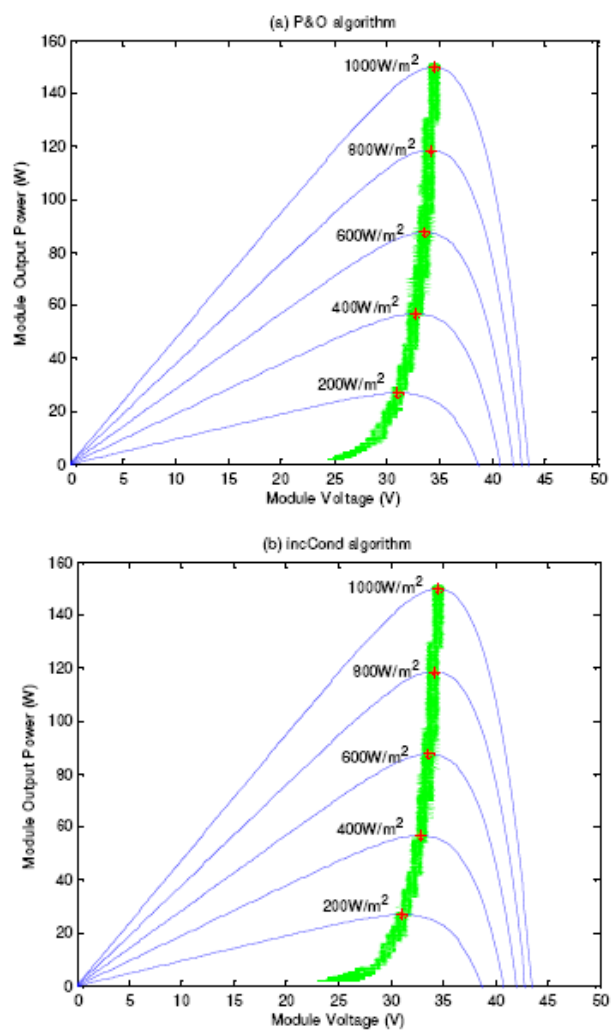

Figure 11. MPP tracking on a sunny day 

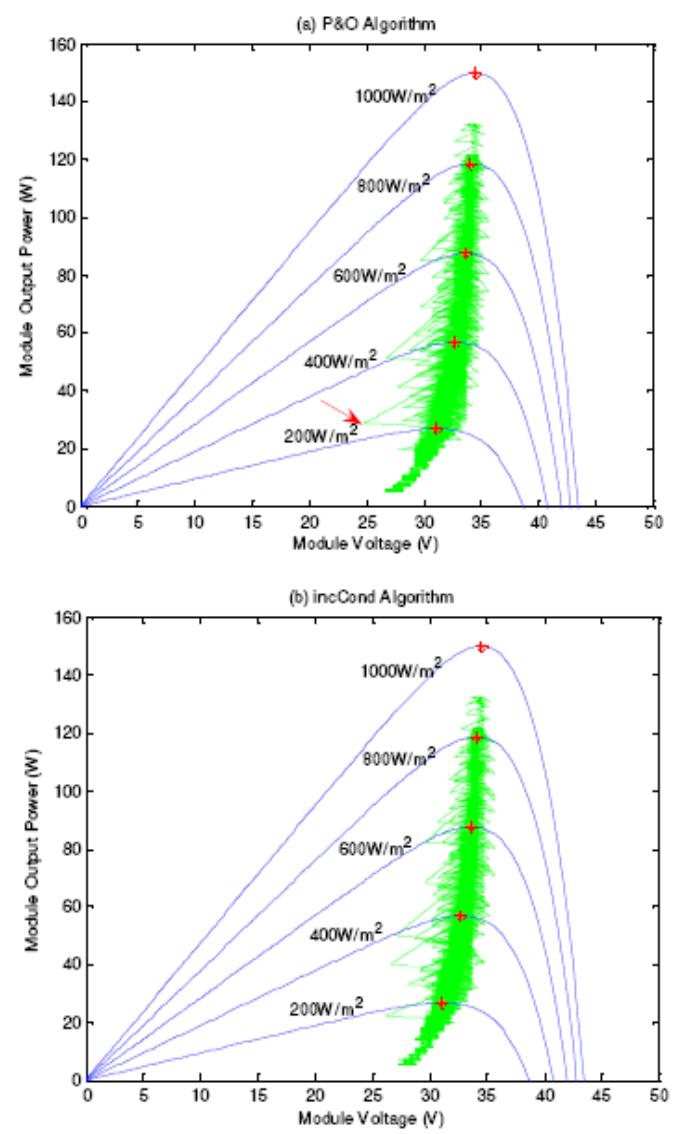

Figure 12. MPP tracking on a cloudy day

The permanent magnet DC motor with a constant field was modeled and simulated with SIMULINK as illustrated in Figure 13. The parameters of DC machine that correspond to the actual pump motor are unknown, thus they are chosen by modification of the default values and estimation from other references [10] [11]. Figure 14 (a) and (b) show that the trace of operating point staying close to the MPPs throughout the simulation.

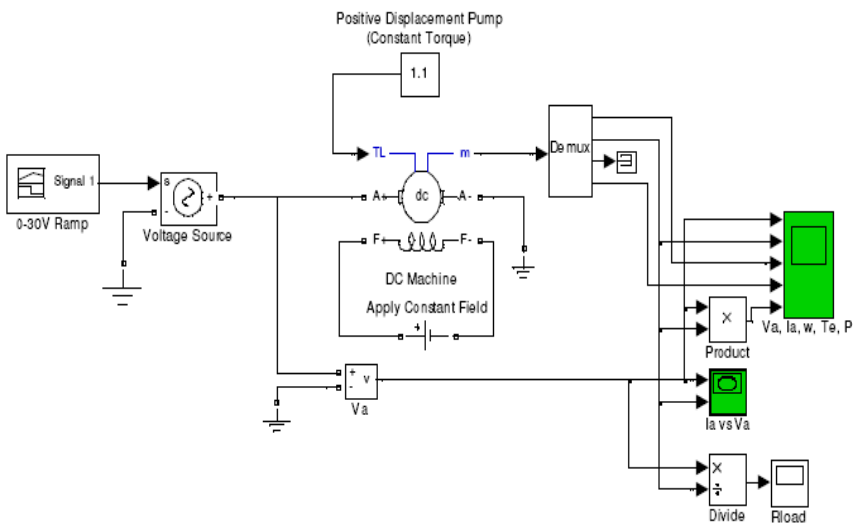

Figure 13. Simulink model for DC Motor (a) PV Power vs. Voltage

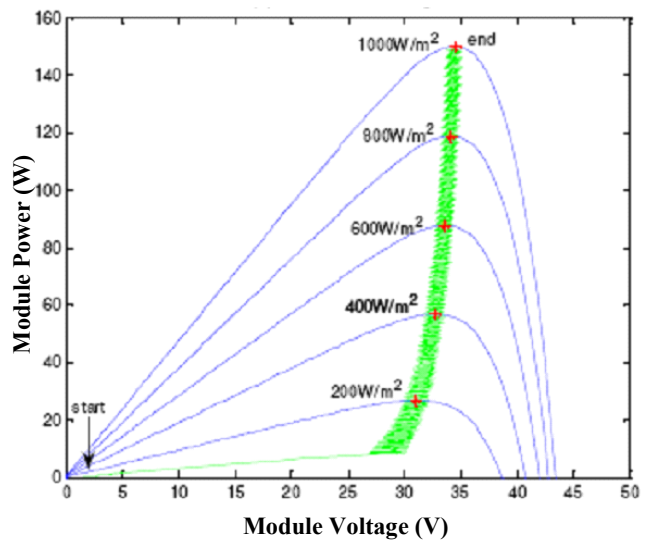

(b) PV Current vs. Voltage

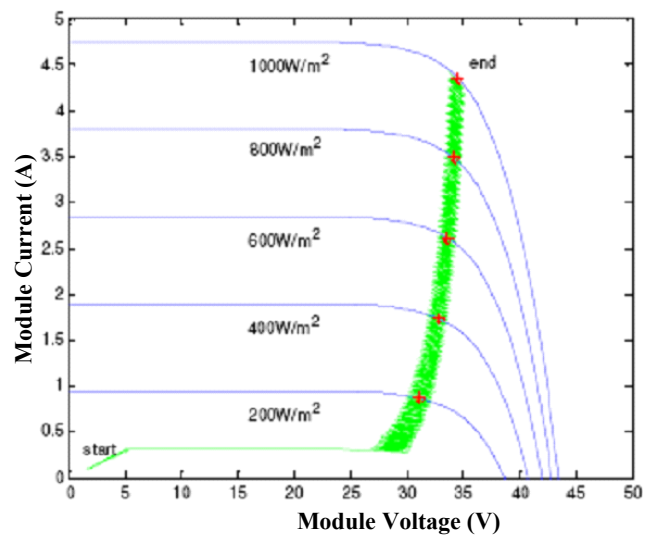

Figure 14. MPPT simulations with the DC pump motor load (20 to $\left.1000 \mathrm{~W} / \mathrm{m} 2,25^{\circ} \mathrm{C}\right)$

Figure 15 shows the $I-V$ curve produced by the SIMULINK simulation. The result was then compared with the direct-coupled PV water pumping system without MPPT. The results as depicted in Figure 15 showed that the PV water pumping system without MPPT has poor efficiency because of mismatching between the PV module and the DC pump motor load. On the other hand, it shows that the system with MPPT can utilize more than $99 \%$ of PV capacity. More specifically, an efficiency increase of $35 \%$ was achieved compared to the system without MPPT.

Figure 15 further emphasizes the severe disadvantage of the direct-coupled PV water pumping system because the pump stays idle for nearly two more hours in the morning while the same system with MPPT is already pumping water. Similarly, it goes idle nearly two hours earlier than the system with MPPT in the afternoon. The flow rate of water is also lower throughout the operating period. The total volume of water pumped for the 12-hour period is also calculated for both systems. The results show that MPPT offers significant performance improvement. It enables to pump up to $87 \%$ more water than the system without MPPT. 


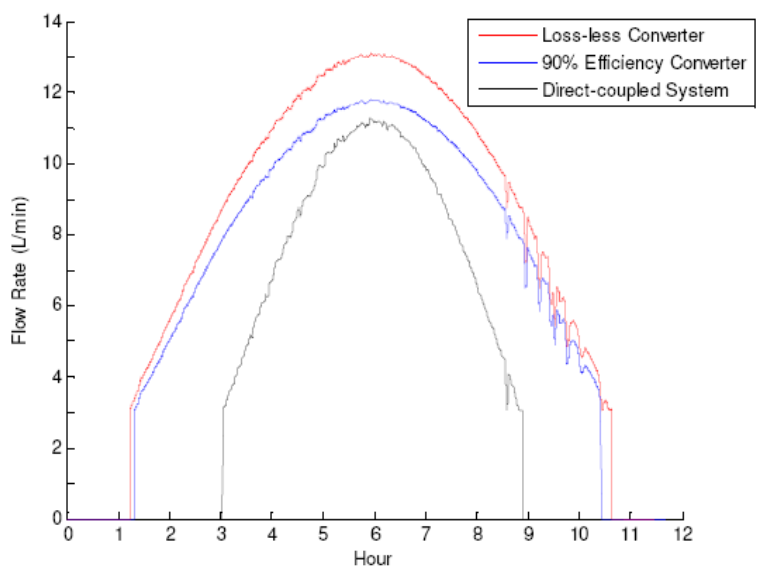

Figure 15. Flow rates of PV water pumps

\section{CONCLUSION}

This paper presents a simple but efficient photovoltaic water pumping system. It models each component and simulates the system using MATLAB and SIMULINK. Simulation of the developed model of the system shows that the PV model using the equivalent circuit in moderate complexity provides good matching with the real PV module. Further, simulations were also performed to compare two MPPT algorithms using actual irradiance data in the two different weather conditions. The incCond algorithm shows narrowly but better performance in terms of efficiency compared to the $\mathrm{P} \& \mathrm{O}$ algorithm under the cloudy weather condition. However, due to cost constraint, the P\&O control method was chosen. Simulation with SIMULINK to model a DC pump motor which was then incorporated into MATLAB verifies functionality and benefits of MPPT. Lastly, simulations of the model were then compared against the system without MPPT in terms of total energy produced and total volume of water pumped a day. The results validate the benefits of the MPPT which can significantly increase the efficiency of energy production from $\mathrm{PV}$ and the performance of the PV water pumping system compared to the system without MPPT.

\section{REFERENCES}

[1]. UNEP "Water Policy and Strategy" (viewed on www.unep.org/dpdl/water/, August 2005)

[2]. UNESCO The UN World Water Development Report, 2003 (viewed on www.unesco.org/water/wwap/wwdr/, August 2005)

[3]. Texas Instruments "Converting Analog Controllers to Smart Controllers with TMS320C2000 DSPs" Application Report, June 2004 (downloaded from dspvillage.ti.com/)

[4]. Rashid, Muhammad H. Editor-in-Chief Power Electronics Handbook Academic Press, 2001

[5]. Kyocera Solar Inc. Solar Water Pump Applications Guide 2001 (downloaded from www.kyocerasolar.com)

[6]. Thompson, Marry A. Reverse-Osmosis Desalination of Seawater Powered by Photovoltaics Without Batteries Doctoral Thesis, Loughborough University, 2003
[7]. Hussein, K. H., I. Muta, T. Hoshino, \& M. Osakada "Maximum Photovoltaic Power Tracking: an Algorithm for Rapidly Changing Atmospheric Conditions" IEE Proceedings - Generation,

Transmission and Distribution - v. 142 January 1995, page 59-64

[8]. Hohm, D. P. \& M. E. Ropp "Comparative Study of Maximum Power Point Tracking Algorithms" Progress in Photovoltaics: Research and Applications November 2002, page 47-62

[9]. MathWorks Inc. Embedded Target for the TI TMS320C2000 ${ }^{\mathrm{TM}}$ DSP Platform For Use with Real-Time Workshop ${ }^{\circledR}$ User's Guide Version 12005

[10]. Castañer, Luis \& Santiago Silvestre Modelling Photovoltaic Systems, Using PSpice John Wiley \& Sons Ltd, 2002

[11]. Sharaf A. M., Abdulla Ismail, R. A. El-Khatib \& S. I. Abu-Azab "A Photovoltaic Utilization System with Bang-Bang Self-Adjusting Maximum Energy Tracking Controller" International Journal of Energy Research, Volume 22, Issue 12 December 1998, page 1091 1098 